\title{
Evaluating hospital design from an operations management perspective
}

\author{
Leti Vos • Siebren Groothuis • \\ Godefridus G. van Merode
}

Received: 13 April 2007 / Accepted: 15 July 2007 / Published online: 22 September 2007

(C) Springer Science + Business Media, LLC 2007

\begin{abstract}
This paper describes an evaluation method for the assessment of hospital building design from the viewpoint of operations management to assure that the building design supports the efficient and effective operating of care processes now and in the future. The different steps of the method are illustrated by a case study. In the case study an experimental design is applied to assess the effect of used logistical concepts, patient mix and technologies. The study shows that the evaluation method provides a valuable tool for the assessment of both functionality and the ability to meet future developments in operational control of a building design.
\end{abstract}

Keywords Operations management · Floor plan design . Research method · Simulation $\cdot$ Health care

\section{Introduction}

In many western countries we observe tendencies towards process driven care. Ideally, the layout of the building should be adjusted to this logistical concept in order to group the facilities along the line of the phases of the care process. This facilitates the integration of various operations in one flow at a rate determined by the needs of a patient and with least amount of delay and waiting [1]. Building a new hospital gives opportunities to match the layout of the hospital

L. Vos $\cdot$ S. Groothuis $(\bowtie) \cdot$ G. G. van Merode

Department of Health Organization Policy

and Economics (HOPE),

Faculty of Health, Medicine and Life Sciences,

Care and Public Health Research Institute (CAPHRI),

Maastricht University,

P.O. Box 616, 6200 MD Maastricht, The Netherlands

e-mail: s.groothuis@beoz.unimaas.nl building with the desired logistical concept. In that case the layout must be suitable to deal with all the flows of patients and goods now and in many years to come. After all, the layout cannot be adapted very easily and only at high cost. Designing a layout is a challenging job because of the uncertainties concerning future numbers of patients, patient mix and new medical technologies. How can we accomplish that the layout of a hospital, which creates conditions for the dynamic operational control, stays appropriate for care delivery in the future?

It is important to design a hospital layout which supports hospital strategy, but also takes the future circumstances and the uncertainties into account. In order to assure that a design supports the efficient and effective operating of care processes now and in the future, it would be useful to have an evaluation method for the assessment of the flexibility and fit of the building design. The purpose of this research is to test such a method and illustrate it by a case. The remainder of this paper is divided into four major sections. First we explain the relationship between the operations management and hospital floor plan design. In the following section a method for evaluation of the flexibility and fit of the building design will be presented. Next this method will be applied in a case study. In the last part we discuss the case and the contribution of the evaluation method for the field of operations management.

\section{Relationship between operations management and hospital design}

From an operations management of view hospitals need to maximize output/ throughput with available resources, taking into account different requirements for delivery flexibility (elective/appointment, semi-urgent, urgent), acceptable 
standards for delivery reliability (waiting list, waiting-times) and acceptable medical outcomes by the design, planning, implementation and control of coordination mechanisms between patient flows and diagnostic and therapeutic activities [2]. In order to realize short throughput times and short displacement distances in the building the different flows between the various locations must be taken into account.

From an architectural view hospitals consist of static floor plans, with elements like corridors, consultation and examination rooms, reception desks, waiting facilities etcetera. From the view of operations management hospitals are systems in which all building elements are related to each other. Persons, goods and information move from one building element to another. This results in flows of people, goods and information. A logistic system has to control these flows and support the hospital's operations.

There is a close link between hospital strategy and the choice of the system for operational planning and control and the hospital's layout. Hospital strategy is an action plan for future development and includes choice of patient mix in terms of disease and treatment and market segments, medical technology and service concept. A realistic horizon for the hospital strategy is always limited: between 5 and 10 years. However the life cycle of a building is much longer. During the life of the building environmental changes may occur, like ageing of population, more demanding patients, and new insights about treatments. This may lead to changes in the hospital's strategy and thus the patient mix, medical technology and the operations management system. This means that the fit between hospital's layout, patient mix and the operations management system is a difficult issue because the time horizons don't match. The cost of changing the layout of an existing hospital building can be enormous. Flexibility of the building to adapt to changes in patient mix, operations management concept and technology is therefore essential.

In this paper we assume that the floor plan design is 'flexible and fit' if it supports and facilitates the operational control now and is appropriate to deal with future developments. The degree of circulation of the flow can be used to measure this flexibility and fit. After all it is congestion of flow that indicates that there is a local capacity problem and thus a non-optimal fit between building design and operational control. In that case the design is not flexible enough to deal with (variations in) the flow. Due to this disturbance in flow in one place, capacity in other places cannot be used in an efficient way [3]. Blockages in the flow can increase waiting and throughput times which have a negative effect on the quality of service delivery and capacity use. The number of people that is walking around and how many goods are transported through the hallways at the same time at the same place in the building is a measure of the degree of circulation or congestion of the flow.

Figure 1 represents the relationship between floor plans and operational planning and control system as described above. On the basis of this model we designed an evaluation method for the flexibility and fit of the building design for operations management, which will be described in the following section.
Fig. 1 Relationship between operations management and hospital design/floor plan

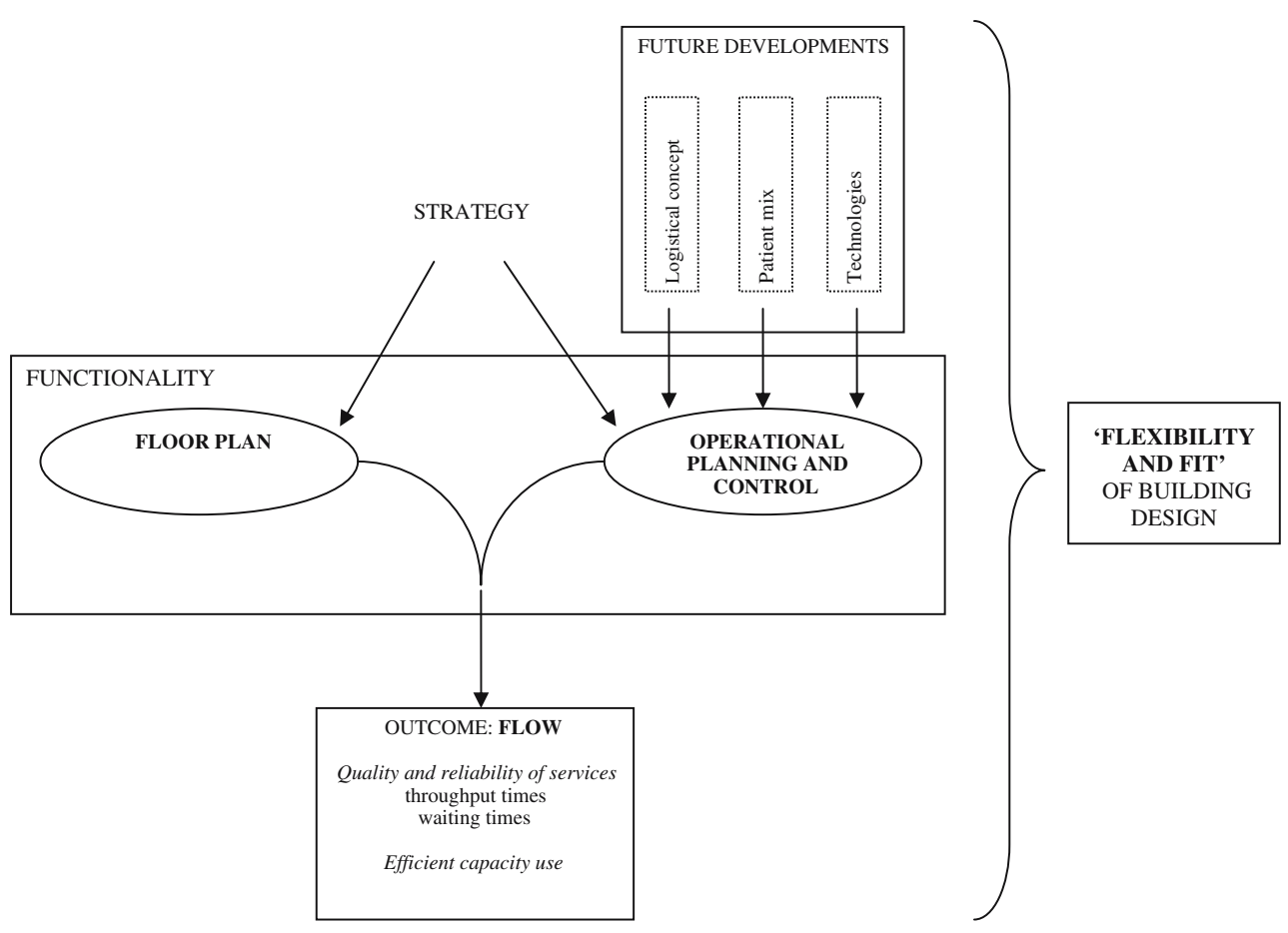




\section{Evaluation method}

In this section a method to evaluate the flow and thus the flexibility and fit of building design will be described (see also Table 1). One of the key features of this method is discrete event simulation.

To determine the degree of circulation of the flow, the hospital system can be defined as a flow system in which different segments of the building are distinguished (step 1). Each segment represents a part of the corridor of the building through which people and goods flow to their destination. Corridors can be divided in segments on basis of function of segments: part of the corridor along receptions desks, along entrances of clinics, along waiting rooms or parts of the corridor which do not have a specific function.

An example is given in Fig. 2. The different segments in this figure are numbered.

The time spent by people and goods in each segment is determined by (walking) speed and the dimensions of each segment. Walking speed can be estimated on $85 \mathrm{~m} / \mathrm{min}$ [4]. After dividing the flow system in segments, the flows, based on floor plans and data on (present) numbers of patients (appointments) and of personnel and the movement of goods, inclusive the logistical planning concept for controlling these flows (push or pull) have to be defined (step 2). Measurement of the degree of circulation based on these flows gives an indication of the functionality of the system. Next an experimental design is developed indicating ranges of changes of flow intensity and direction (result of change of logistical concept), and on changes or increase of intensity of the flow (result of changed patient mix and new technologies) (step 3). The next step is assessing the number of people and goods which are present on the same place at the same time in the different experimental scenarios (step 4).

To accomplish the above steps a discrete event simulation model has been build. Discrete event simulation is the modeling of a system as it evolves over time by representation in which state variables changes instantaneously at separate points in time [5]. The floor plan of the hospital is represented as segments in the simulation model.

Table 1 Steps of the evaluation method

\begin{tabular}{ll}
\hline Step Number & \\
\hline 1 & Distinguish segments of the floor plan \\
2 & Determine flows of persons and goods \\
3 & Design experiments \\
4 & Implement the model \\
5 & Run the simulation model, experiment \\
& and analyze the results \\
\hline
\end{tabular}

Furthermore the simulation model contains the expected amount of flows of people and goods. The segments are locations with limited capacity.

The number of people in a segment is represented by the performance indicator of maximum value of the number of people who are present on the same time in the same segment. The floor plan design has to be able to deal with this maximum number of people. Therefore it is important to assess this maximum value. Besides the maximum value it is even more important to know how often this maximum value occurs within single timeslots of one hour. Step five exists of running the simulation model (to test functionality). In this phase several experiments regarding flow intensity and direction can be done (to test the ability to adapt to developments). These experiments are determined according to an experimental design [6]. After simulation results have to be interpreted. The steps described above are summarized in Table 1. The usefulness of this method is illustrated in a case study.

\section{Case study}

In this section we apply this method for the evaluation of the flexibility and fit of the design for operations management to a case. The case selected concerns a new Dutch hospital which is the result of the merger of two hospitals and will be build on a new location. This new hospital wants to introduce a ' $21^{\text {st }}$ century airport' operations management concept for the design of an outpatient clinic. The purpose of the 'twenty-first century airport' concept is the efficient use of space of the hospital building by centralizing the waiting areas. The assessment answers the question whether the hospital design will allow a free flow of persons and goods.

\subsection{Setting}

The outpatient clinic has one central waiting area and a limited waiting capacity in the different ambulatory departments. Each ambulatory department has its own reception desk, which is located along the main corridors. Two rooms for consultation and/ or examining patients are available for each medical specialist. According to the ' $21^{\text {st }}$ century airport' concept patients and their companions will wait in the central waiting area for a call to leave for their destination: the ambulatory department of their specialist. Every ambulatory department is situated at a main corridor. Patients take the main corridor to walk to their destination. The ' $21^{\text {st }}$ century airport' concept assumes that no patients and companions have to wait at the ambulatory departments. This means that the consultation or examination room is directly available at the time the patient en his 


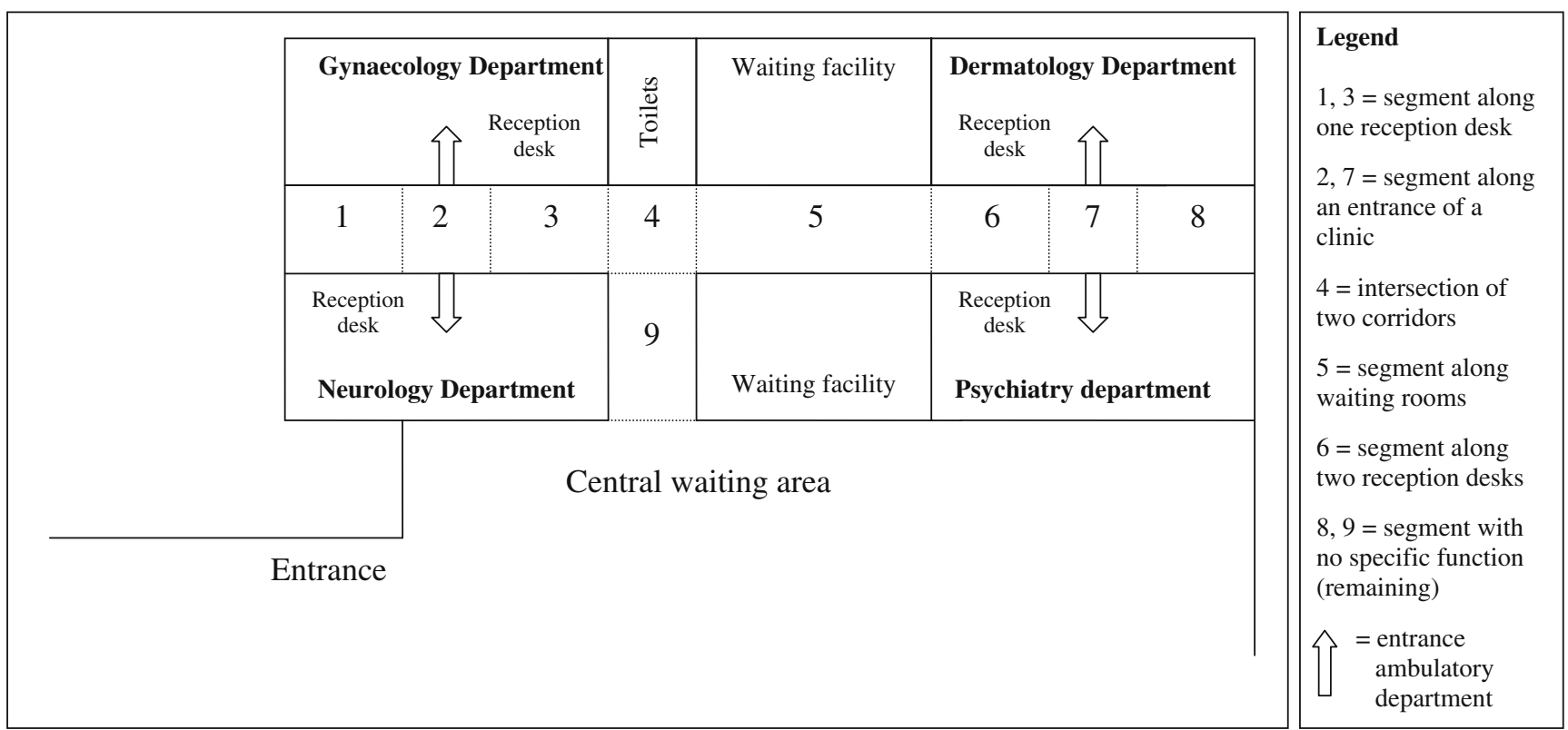

Fig. 2 Example of division in segments

companion arrives at the ambulatory department. A patient will only move from one room, e.g. a consultation room to another room, e.g. an examination room at the department when the examination room is available. This logistical concept can only be applied to highly standardized patients groups. The flow of these patients is certain. The successive care activities (consultations, examinations, diagnostics, and treatments) are already planned before the patient arrives at the hospital. Non standard patients will wait in (highly equipped) rooms before they can go to another room. After their visit some patients make a new appointment at the reception desk. The number of patients that will make an appointment differs per specialism. Also personnel walk through the corridors to their destination at the beginning and end of their working day.

Data concerning the routing of the present patient mix and staff were provided by the hospital. The hospital provided also the data concerning the working hours of the staff. These data were considered as facts and were not subject of this research. Data on the movement of goods were not available and therefore not included in this study.

\subsection{Methodology}

This paragraph describes how the evaluation method is used in the case described above (see Table 1).

Step 1. Distinguish segments of the floor plan. To measure the degree of circulation the corridors of the outpatient's clinic have been divided in segments on basis of available floor plans. Each segment represents a part of the corridor. The segments can be classified in five categories: segments with one reception desk at the side of the corridor, segments with two reception desks, segments which are part of an intersection of two corridors, segments which are part of a main way to another building, remaining segments (Fig. 2). The width of each segment was 2.55 meter, the lengths varied from 2 to $5.4 \mathrm{~m}$.

Step 2. Determine flows of persons and goods. For this case data were available on (present) numbers of patients (appointments) and of personnel in the two hospitals and were extrapolated by the hospital to the new hospital. The hospital assumes that $50 \%$ of the patients will be accompanied by one person and the other $50 \%$ by two persons. On basis of these data expected flows are defined to assess the functionality of the design. To control the flows on the outpatient clinic the hospital uses a pull system in line with the proposed logistical concept. In order to have the right patient on the right time on the right place, the hospital tries to reduce the variation in arrivals at the departments by the creation of a central waiting area. From this area patients are asked at a specific moment to move to a specific location at the department. This moment is determined by the availability of the needed resources (staff and/or equipment).

Step 3. Design experiments. According to the presented model in Fig. 1 uncertainties in flow intensity can be the result of three factors: used logistical concept, and development of patient mix and 
technologies. The ability of the design of the outpatients' clinic to meet these uncertainties is assessed in an experimental design. Therefore we determined three parameters: arrival pattern (logistical concept, intensity of the flow), number of patients (patient mix and technologies) and the duration of making an appointment (logistical concept, flow direction). Three values are used for simulating different arrival patterns (parameter 1) at the ambulatory departments of the outpatients' clinic in the experimental design: arrival schedule A (arrivals per hour determined by means of a probability distribution), arrival schedule $\mathrm{B}$ (patients arrive every 10 min with an uncertainty of $5 \mathrm{~min}$ ), arrival schedule $\mathrm{C}$ (patients arrive every $10 \mathrm{~min}$ with an uncertainty of $2 \mathrm{~min}$ ). Parameter 2 , number of patients, which concerns the flow intensity, has only two values: the present number of patients and a situation in which the number of patients increased with $25 \%$. Parameter 3, the duration of the process of making an appointment, has also two values: $T(1,2,3)$ [triangular distribution (minimum, modus, maximum)] and $T(1.5$, 2.5, 3.5). A full experimental design was applied which resulted in 12 experiments (see Table 2). This study assessed one fixed logistical concept and therefore this was not a factor in the experimental design.

Step 4. Implement the model. In our case the model is implemented in MedModel [7]. MedModel is a discrete event simulation environment with a graphical interface.

Step 5. Run the simulation model, experiment and analyze the results. We simulated 100 days (100 replications). We also simulated single timeslots (see Section 3).

\subsection{Results}

The results concern the flow of patients, companions, staff and visitors. Data were gathered for each of the hundred replications.

Functionality For the results of the simulation of the expected flows see Table 3, schedule A. The results for seven segments of the main corridors of the outpatients' clinic are presented. These seven segments represent the five categories as described above. These results show that there are more people in corridors with reception desks at the side of it.

Ability to meet future developments To assess the ability of the system to meet future developments we performed the 12 experiments of the experimental design. Table 3 shows the results of experiment 1,2 and 3: the simulation of several arrival patterns in arrival schedules A, B and C. The values measured per schedule do not differ significantly. A minimum value of the maximum number of patients represents the lowest maximum number of patients that is present at the same time in a segment in hundred days. A maximum value of 18 means that there were 18 people at the same time present in the same segment on at least one day (of the hundred days simulated). The same values were measured when we collected data during specific time slots, e.g. from 9:00 till 10:00 A.M. Only during lunch break of personnel the maximum values decreased.

When the patients' stay at the reception desk increased with half a minute $T(1.5,2.5,3.5)$ but the number of people remained the same in experiment 7,8 and 9 , the maximum values were not affected (see Table 4).

The results of experiment 7,8 and 9 which assesses increase of flow volume, show that the maximum values

Table 2 Experiments

\begin{tabular}{|c|c|c|c|c|c|c|c|}
\hline \multirow[t]{2}{*}{ Experiment } & \multicolumn{3}{|c|}{ Arrival Pattern } & \multicolumn{2}{|c|}{ Number of Patients } & \multicolumn{2}{|c|}{ Duration of Making an Appointment } \\
\hline & $\mathrm{A}$ & $\mathrm{B}$ & $\mathrm{C}$ & Present Number & $+25 \%$ & $T(1,2,3)$ & $T(1.5,2.5,3.5)$ \\
\hline 1 & $\mathrm{X}$ & & & $\mathrm{X}$ & & $\mathrm{X}$ & \\
\hline 2 & & $\mathrm{X}$ & & $\mathrm{X}$ & & $\mathrm{X}$ & \\
\hline 3 & & & $\mathrm{X}$ & $\mathrm{X}$ & & $\mathrm{X}$ & \\
\hline 4 & $\mathrm{X}$ & & & $\mathrm{X}$ & & & $\mathrm{X}$ \\
\hline 5 & & $\mathrm{X}$ & & $\mathrm{X}$ & & & $\mathrm{X}$ \\
\hline 6 & & & $\mathrm{X}$ & $\mathrm{X}$ & & & $\mathrm{X}$ \\
\hline 7 & $\mathrm{X}$ & & & & $\mathrm{X}$ & $\mathrm{X}$ & \\
\hline 8 & & $\mathrm{X}$ & & & $\mathrm{X}$ & $\mathrm{X}$ & \\
\hline 9 & & & $\mathrm{X}$ & & $\mathrm{X}$ & $\mathrm{X}$ & \\
\hline 10 & $\mathrm{X}$ & & & & $\mathrm{X}$ & & $\mathrm{X}$ \\
\hline 11 & & $\mathrm{X}$ & & & $\mathrm{X}$ & & $X$ \\
\hline 12 & & & $X$ & & $X$ & & $X$ \\
\hline
\end{tabular}


Table 3 Results of experiment 1, 2 and 3

\begin{tabular}{|c|c|c|c|c|c|c|c|c|c|c|}
\hline \multirow[t]{3}{*}{ Segment (Category) } & \multirow{3}{*}{$\begin{array}{l}\text { Dimensions } \\
\text { (Meters) }\end{array}$} & \multicolumn{9}{|c|}{ More Strictly Organized Arrival Pattern } \\
\hline & & \multicolumn{3}{|c|}{ Schedule A } & \multicolumn{3}{|l|}{ Schedule B } & \multicolumn{3}{|l|}{ Schedule C } \\
\hline & & Minimum & Maximum & Median & Minimum & Maximum & Median & Minimum & Maximum & Median \\
\hline B11 (2), 2 reception desks & $5.4 \times 2.55$ & 6 & 14 & 9 & 6 & 10 & 8 & 8 & 12 & 9 \\
\hline B13 (1), 1 reception desk & $5.4 \times 2.55$ & 9 & 18 & 11 & 6 & 11 & 8 & 7 & 12 & 9 \\
\hline B14 (3), intersection & $2 \times 2.55$ & 4 & 9 & 6 & 4 & 9 & 6 & 5 & 9 & 6 \\
\hline $\begin{array}{l}\text { D11 (5), no specific } \\
\text { function }\end{array}$ & $5.4 \times 2.55$ & 7 & 15 & 9 & 7 & 14 & 9 & 7 & 13 & 9 \\
\hline $\begin{array}{l}\text { D13 (5), no specific } \\
\text { function }\end{array}$ & $5.4 \times 2.55$ & 4 & 10 & 6 & 4 & 9 & 6 & 4 & 10 & 6 \\
\hline F5 (1), one reception desk & $5.4 \times 2.55$ & 9 & 18 & 11 & 8 & 14 & 9 & 9 & 15 & 11 \\
\hline $\begin{array}{l}\text { F16 (4), corridor to } \\
\text { psychiatric centre }\end{array}$ & $5.4 \times 2.55$ & 8 & 18 & 12 & 8 & 20 & 12 & 6 & 24 & 12 \\
\hline
\end{tabular}

Maximum value of number of people in a segment (100 replications) and the service time at a desk is $T(1,2,3)$ distributed for different schedules. The segments can be classified in five categories: segments with one reception desk at the side of it (1), segments with two reception desks (2), segments which are part of a intersection of two corridors (3), segments which are part of a main way to another building (4), segments with no specific function (remaining; 5).

increased with one or two persons when then number of patients increased with $25 \%$ (see Table 5).

In experiment 10,11 and 12 both the number of patients as the duration of the process are increased. The results are presented in Table 6 .

\section{Implications and conclusion}

First the results of the case will be discussed. Then the contribution of the evaluation method for the assessment of the flexibility and fit of building design will be outlined.

\subsection{Discussion and conclusion of the case study}

The evaluation method showed that the floor plan design of the outpatient clinic supports the functionality of the system and facilitates expected flows. The results of arrival schedule 1 experiment 1 showed the expected maximum number of persons in the different locations of a hospital building given the proposed logistical concept. Any higher value for the number of people in a certain segment indicates a higher possibility of congestion of the flow. The segments along reception desk(s) seem the locations which are most sensitive for congestion. But no real

Table 4 Results of experiment 4, 5 and 6

\begin{tabular}{|c|c|c|c|c|c|c|c|c|c|c|}
\hline \multirow[t]{3}{*}{ Segment (Category) } & \multirow{3}{*}{$\begin{array}{l}\text { Dimensions } \\
\text { (Meters) }\end{array}$} & \multicolumn{9}{|c|}{ More Strictly Organized Arrival Pattern } \\
\hline & & \multicolumn{3}{|l|}{ Schedule A } & \multicolumn{3}{|l|}{ Schedule B } & \multicolumn{3}{|l|}{ Schedule C } \\
\hline & & Minimum & Maximum & Median & Minimum & Maximum & Median & Minimum & Maximum & Median \\
\hline B11 (2), 2 reception desks & $5.4 \times 2.55$ & 8 & 17 & 10 & 7 & 11 & 8 & 8 & 13 & 9 \\
\hline B13 (1), 1 reception desk & $5.4 \times 2.55$ & 9 & 18 & 12 & 7 & 11 & 8 & 7 & 12 & 9 \\
\hline B14 (3), intersection & $2 \times 2.55$ & 5 & 9 & 6 & 4 & 7 & 6 & 4 & 8 & 6 \\
\hline $\begin{array}{l}\text { D11 (5), no specific } \\
\text { function }\end{array}$ & $5.4 \times 2.55$ & 7 & 14 & 9 & 7 & 13 & 9 & 7 & 15 & 10 \\
\hline $\begin{array}{l}\text { D13 (5), no specific } \\
\text { function }\end{array}$ & $5.4 \times 2.55$ & 4 & 8 & 6 & 4 & 9 & 6 & 4 & 10 & 6 \\
\hline F5 (1), one reception desk & $5.4 \times 2.55$ & 9 & 20 & 13 & 8 & 16 & 11 & 9 & 17 & 11 \\
\hline $\begin{array}{c}\text { F16 (4), corridor to } \\
\text { psychiatric centre }\end{array}$ & $5.4 \times 2.55$ & 8 & 18 & 12 & 6 & 16 & 12 & 8 & 18 & 12 \\
\hline
\end{tabular}

Maximum value of number of people in a segment (100 replications) and the service time at a desk is $T(1.5,2.5,3.5)$ distributed for different schedules. 
Table 5 Results of experiment 7,8 and 9

\begin{tabular}{|c|c|c|c|c|c|c|c|c|c|c|}
\hline \multirow[t]{3}{*}{ Segment (Category) } & \multirow{3}{*}{$\begin{array}{l}\text { Dimensions } \\
\text { (Meters) }\end{array}$} & \multicolumn{9}{|c|}{ More Strictly Organized Arrival Pattern } \\
\hline & & \multicolumn{3}{|c|}{ Schedule A } & \multicolumn{3}{|l|}{ Schedule B } & \multicolumn{3}{|l|}{ Schedule C } \\
\hline & & Minimum & Maximum & Median & Minimum & Maximum & Median & Minimum & Maximum & Median \\
\hline B11 (2), 2 reception desks & $5.4 \times 2.55$ & 8 & 15 & 11 & 7 & 11 & 9 & 8 & 12 & 10 \\
\hline B13 (1), 1 reception desk & $5.4 \times 2.55$ & 9 & 20 & 13 & 8 & 12 & 10 & 10 & 16 & 11 \\
\hline B14 (3), intersection & $2 \times 2.55$ & 5 & 9 & 6 & 5 & 9 & 6 & 5 & 11 & 6 \\
\hline $\begin{array}{l}\text { D11 (5), no specific } \\
\text { function }\end{array}$ & $5.4 \times 2.55$ & 4 & 8 & 6 & 4 & 12 & 6 & 4 & 14 & 6 \\
\hline $\begin{array}{l}\text { D13 (5), no specific } \\
\text { function }\end{array}$ & $5.4 \times 2.55$ & 9 & 22 & 14 & 9 & 15 & 10 & 10 & 17 & 11 \\
\hline F5 (1), one reception desk & $5.4 \times 2.55$ & 9 & 22 & 14 & 9 & 15 & 10 & 10 & 17 & 10 \\
\hline $\begin{array}{l}\text { F16 (4), corridor to } \\
\text { psychiatric centre }\end{array}$ & $5.4 \times 2.55$ & 8 & 18 & 12 & 8 & 22 & 12 & 10 & 20 & 12 \\
\hline
\end{tabular}

Maximum value of number of people in a segment (100 replications) and the service time at a desk is $T(1,2,3)$ distributed for different schedules with an increased number of patients.

problems did occur during the simulation experiments. So the floor plan design can be considered to be functional given the expected situation. The ability to meet future developments is assessed in the twelve experiments. These experiments showed that there is a small difference between the median of the maximum values and the overall maximum value in the three arrival schedules (see Table 3 ). The results from experiment 4-6 and 10-12 indicate that the placement of reception desks directly along the corridors also influences the flow. When the duration of the processes at reception desks (which are directly placed along the corridors) is extended, the maximum values of the number of people in the segments are higher. Experiment 7-12 shows us that when the number of patients increases the limitations of and requirements on layout are more evident.
These results show the importance of the evaluation of a floor plan design. In this case the building seems to support the functionality of the system and facilitates expected flows. However, the case study shows that if the flows change in intensity, direction or volume the maximum number of patients in the segments increases and this will lead to congestion. The design seems not flexible enough to deal with variations in the factors mentioned above: used logistical concept, patient mix and technologies. The intended operations management system assumes that patient routings can be standardized and completely controlled once started. According to the hospital management variation in the flow will decrease after the implementation period of ' $21^{\text {st }}$ century airport' concept. The hospital management is taking an enormous risk by constructing a hospital building that allows a limited

Table 6 Results of experiment 10, 11 and 12

\begin{tabular}{|c|c|c|c|c|c|c|c|c|c|c|}
\hline \multirow[t]{3}{*}{ Segment (Category) } & \multirow{3}{*}{$\begin{array}{l}\text { Dimensions } \\
\text { (Meters) }\end{array}$} & \multicolumn{9}{|c|}{ More Strictly Organized Arrival Pattern } \\
\hline & & \multicolumn{3}{|c|}{ Schedule A } & \multicolumn{3}{|l|}{ Schedule B } & \multicolumn{3}{|l|}{ Schedule C } \\
\hline & & Minimum & Maximum & Median & Minimum & Maximum & Median & Minimum & Maximum & Median \\
\hline B11 (2), 2 reception desks & $5.4 \times 2.55$ & 9 & 16 & 11 & 7 & 10 & 9 & 8 & 13 & 10 \\
\hline B13 (1), 1 reception desk & $5.4 \times 2.55$ & 11 & 23 & 14 & 9 & 16 & 10 & 9 & 16 & 11 \\
\hline B14 (3), intersection & $2 \times 2.55$ & 5 & 9 & 6 & 5 & 10 & 6 & 5 & 9 & 6 \\
\hline $\begin{array}{l}\text { D11 (5), no specific } \\
\text { function }\end{array}$ & $5.4 \times 2.55$ & 8 & 14 & 10 & 7 & 13 & 9 & 8 & 16 & 10 \\
\hline $\begin{array}{l}\text { D13 (5), no specific } \\
\text { function }\end{array}$ & $5.4 \times 2.55$ & 4 & 10 & 6 & 4 & 8 & 6 & 4 & 9 & 6 \\
\hline F5 (1), one reception desk & $5.4 \times 2.55$ & 12 & 27 & 16 & 9 & 22 & 12 & 7 & 19 & 13 \\
\hline $\begin{array}{c}\text { F16 (4), corridor to } \\
\text { psychiatric centre }\end{array}$ & $5.4 \times 2.55$ & 8 & 20 & 12 & 8 & 18 & 12 & 10 & 18 & 12 \\
\hline
\end{tabular}

Maximum value of number of people in a segment (100 replications) and the service time at a desk is $T(1.5,2.5,3.5)$ distributed for different schedules with an increased number of patients. 
variation in flow. We recommend to increase the flexibility and fit of the building design through the creation of decentralized waiting rooms at the ambulatory departments. Decentralized waiting rooms can counteract the effect of fluctuations in the flow. Besides this, more flexibility can be created through standardization of rooms, especially consultation rooms. Both the addition of decentralized waiting rooms and standardization of consultation rooms will reduce the dependency on the used logistical concept and thus increase the flexibility and improve the fit of the building design.

In this case study no waiting times at the ambulatory department were taken into account because of the assumption made by the hospital management that the patients will be directly seen by the medical specialist after their arrival at the ambulatory department. This assumption is an essential part of the operations management concept where patients are paged from a central waiting area to a specific care unit when the medical specialist becomes available ('pull' logistics). The presence of privacy lines before reception desks, which has a reducing effect on available capacity in segments could also not be simulated. These privacy lines would almost certainly have a disturbing effect on the flows. Further, except lunch break, no movements of personnel during office hours are simulated because of unavailability of data. These movements are additional to the movements modeled in the simulation model and therefore will increase the determined maximum values.

\subsection{Discussion of the simulation model}

The simulation model provided information about the number of persons in a certain segment. In the simulation model all persons have a constant walking behavior. We can imagine that people in particular cases slow down or will stop to look around which direction the have to go e.g. when they are approaching a corridor or crossing. This kind of behavior is not included in the model. Also effects of the use of wheelchairs, rollators, stretchers and buggies have not been taken into account. These movement aids will take more space and progress slower than a single person does, which will disturb the flow with great probability. Enlarging the scope of the simulation model will allow an assessment in greater detail. To extend the simulation model asks for further research.

\subsection{Contribution of the evaluation method}

This research tried to fill the gap between the world of architecture and the world of operational control. Flexibility and fit of a building design implies that the static floor plan, made by the architect, meets the requirements of the dynamics of operational control. The case study shows that discrete event simulation is a useful technique for the evaluation of the flexibility and fit of a building for operations management. Both functionality and the ability to meet future developments of the design can be assessed. When the capacity meets the requirement to deal with the flows in combination with the chosen logistical concept, the building can be considered to be functional. This can be assessed through a simulation study of the expected situation. The ability to meet future developments can be determined through simulation of variations in future developments such as used logistical concept, patient mix and technology. The techniques used in this study are not only useful for evaluation of the new designs. Simulation can also be used for the evaluation of new logistic concepts for care processes in existing buildings. Specific experiments can be designed to assess the implications of the logistical concept. Evaluation of new logistic concepts before introducing them can prevent the occurrence of problems in the overall flow system.

Assessing the flexibility and fit of a building in the design phase is in our opinion of great importance for operations management. In this phase it is still possible to adjust the layout of the building. We illustrated the usefulness of the evaluation method with a case. In this example the building design shows shortcomings regarding the ability to meet future developments. Because of this evaluation, the design of the outpatient clinic can be adjusted in order to reach a higher degree of flexibility and fit for operations management and thus a higher durability.

Acknowledgement This study was financially supported by MESOS hospital Utrecht, The Netherlands.

\section{References}

1. Liker JK (2004) The Toyota way: 14 management principles from the world's greatest manufacturer. McGraw-Hill, New York

2. de Vries G, Bertrand JWM, Vissers JMH (1999) Design requirements for health care production control systems. Prod Plan Control 10(6):559-569

3. van Merode GG, Groothuis S (2003) Hospitals as complexes of queuing systems. In: Anderson JG, Katzper M (ed) Health sciences simulation 2003. Society for Modeling and Simulation International (SCS), Orlando, FL

4. Abernethy B, Hanrahan SJ, Kippers V, Mackinnon LT, Pandy MG (2005) The biophysical foundations of human movement. Human Kinetics, Champaign, IL

5. Law AM, Kelton WD (1991) Simulation modeling and analysis, 2nd ed. McGraw-Hill, New York

6. Banks J (1998) Handbook of simulation: principles, methodology, advances, applications, and practice. Wiley, New York

7. MedModel homepage. http://www.promodel.com/products/medmodel. Cited 10 May 2005 